\title{
LA VULNERABILIDAD INTENCIONADA DURANTE LA DICTADURA EN CHILE, EN LAS NOVELAS LA LITERATURA NAZI EN AMÉRICA, ESTRELLA DISTANTE Y NOCTURNO DE CHILE, DE ROBERTO BOLAÑO
}

Intentional vulnerability During Chile’s Dictatorship in Roberto Bolaño’s Nazi Literature in America, Distant Star and By Night in Chile

Diana Elena García Castillo, Benemérita Universidad Autónoma de Puebla Correo electrónico: dianaelenagarcia5@gmail.com

Recepción: 2020/01/31

Aceptación: 2020/07/28

Resumen. Las novelas La literatura nazi en América, Estrella distante y Nocturno de Chile, del escritor Roberto Bolaño, vislumbran que la vulnerabilidad de algunos personajes es un asunto intencionado y de interdependencia que se despliega en secuestro, tortura, asesinato y desaparición forzada a consecuencia de una subjetivación que sale de la norma que establece el poder de Estado neoliberal. Apoyo mis aseveraciones en la noción de vulnerabilidad e interdependencia que desarrolla Judith Butler, en el planteamiento de Adriana Fuentes sobre subjetividad, y en la propuesta de David Harvey acerca del neoliberalismo. El objetivo es mostrar cómo estas narrativas de Roberto Bolaño dialogan con personajes vulnerables que fueron aniquilados sistemáticamente a causa de una ideología política discrepante con los principios neoliberales. Mediante las reflexiones del artículo llego a la conclusión de que la postura de Bolaño al escribir sobre los personajes disidentes políticos es la de visibilizarlos como cuerpos que importan.

Palabras clave: vulnerabilidad, subjetivación, interdependencia, poder soberano.

\begin{abstract}
Roberto Bolaño's Nazi Literature in America, Distant Star and By Night in Chile show that the vulnerability of some characters is an intentional and interdependent issue that unfolds in kidnapping, torture, murder and forced disappearance as a result of a subjectivation that goes beyond the norm established by the neo-liberal state power. I support my assertions in Judith Butler's notion of vulnerability and interdependence, Adriana Fuentes's approach to subjectivity, and David Harvey's proposal about neoliberalism. The objective is to show how these narratives are in a dialogue with vulnerable characters who were systematically annihilated because of a political ideology that disagrees with neoliberal principles. Through the reflections of the article, I conclude that Bolaño's position in writing about political dissidents is to make them visible as bodies that matter.
\end{abstract}

Keywords: vulnerability, subjectivation, interdependence, sovereign power. 


\section{Introducción}

Las novelas La literatura nazi en América, Estrella distante y Nocturno de Chile encuentran su coincidencia en el tema de las desapariciones forzadas durante la época de la dictadura chilena. La última parte de La literatura nazi, titulada "Ramírez Hoffman, el infame", corresponde a la etapa de aeronauta de las Fuerzas Armadas de Chile del personaje principal. Además de aviador, Ramírez Hoffman es infiltrado de la dictadura, artista plástico y poeta asistente al taller de poesía de Juan Cherniakowski. Estrella distante es una novela que profundiza en aspectos que aparecen previamente en La literatura nazi, particularmente en los crímenes con matices de nuevas metáforas del arte, con lo cual se manifiesta la importancia de comprender al cuerpo desde la complejidad y mediante todas posibles expresiones como el pensamiento político, la poesía, el gusto o el dolo. Por su parte, Nocturno de Chile plantea la complicidad de quienes asistieran a las tertulias literarias en casa de la escritora María Canales ante las torturas que dirigía su esposo, Jimmy Thompson, y que se llevaban a cabo en el sótano de la misma casa.

Históricamente, los saberes que han regido la visión del mundo están basados en la representación binaria de las categorías de bien y mal. Del lado del bien se han establecido prácticas corporales literarias, apelando a que la "literatura y la cultura letrada [son] instrumentos de progreso, civilización y humanización", ${ }^{1}$ recreativos, deleitables y pedagógicos, principalmente, siempre y cuando estas prácticas sean afines a las ideologías políticas del poder hegemónico. Sin embargo, la narrativa de Bolaño rompe con este paradigma al relatar las historias de personajes escritores, lectores y talleristas de poesía, quienes aparecen señalados como vidas que no merecen vivir. Puesto que, desde el mal como oposición del bien, se han situado prácticas que no corresponden a la heteronormatividad que define el comportamiento esperado de los sujetos, como que las mujeres ocupen espacios públicos más allá del mercado o la iglesia. ¿Qué hace posible que esos personajes sean asumidos como vidas no vivibles? ¿Desde qué perspectiva son vistos como sujetos que merecen morir? ¿Cómo es el discurso que los encubre y justifica la violencia como un asunto de merecimiento? ¿Cuál es la postura que manifiestan las novelas mencionadas de Roberto Bolaño ante esas corporeidades?

\footnotetext{
${ }^{1}$ Ignacio López, "Malestar en la literatura: escritura y barbarie en Estrella distante y Nocturno de Chile de Roberto Bolaño", Revista Chilena de Literatura, núm. 20 (2009): 201.
} 
Estas narrativas de Roberto Bolaño permiten reflexionar acerca de la vulnerabilidad desde la perspectiva en que es enunciada por Judith Butler como una cualidad innata a los seres vivos. De manera que, para ella, "la vulnerabilidad no puede ser concebida de manera limitada, como un efecto restringido a una situación contingente o como una mera disposición subjetiva", 2 sino como "una condición que coexiste con la vida humana concebida como vida social y ligada al problema de la precariedad-, la vulnerabilidad es el nombre atribuido a una cierta manera de apertura al mundo". ${ }^{3}$ Dentro y fuera de los textos literarios, la vulnerabilidad ha sido uno de los rasgos con los que se han subjetivado a las corporeidades que viven en pobreza, a los migrantes o a quienes están en la guerra. Este texto no quiere contrariar la persistencia del peligro al que están expuestos esos grupos sociales. Sin embargo, defiendo que el uso del término para tales circunstancias pone en entredicho la existencia de un interés por visibilizar y acentuar la fragilidad de la vida sólo en algunos grupos sociales y negarla en otros para fingir indestructibilidad y justificar el daño que pueden ocasionar. En las novelas de Bolaño, dicha visibilización ocurre en un contexto político económico de sesgo neoliberal, en el que el "bienestar del ser humano consiste en no restringir el libre desarrollo de las capacidades y de las libertades empresariales del individuo dentro de un marco institucional caracterizado por derechos de propiedad privada fuertes, mercados libres y libre comercio". ${ }^{4}$ Sin embargo, ese libre desarrollo contrasta con la represión y la vulnerabilidad intencionada a la que se ven sometidos los personajes de las mencionadas novelas escritas por Bolaño.

De los textos sobre los que aquí se reflexiona, la semblanza biográfica del escritor Silvio Salvático, en La literatura nazi en América, podría considerarse una sección que explora parte del origen de los saberes de exclusión que justifican y desean la violencia hacia determinados sujetos. Las ideas presentes desde los primeros escritos en la obra de Salvático son "el exterminio de los indios para evitar una mayor contaminación de la raza argentina". 5 Con la expresión "exterminio de los indios" se manifiesta la prioridad por salvaguardar las marcas corporales de tez clara de los argentinos, que los asemeja y vincula

\footnotetext{
2 Judith Butler, "Vida precaria, vulnerabilidad y ética de cohabitación”, en Begonya Saez Tajafuerce (ed.), Cuerpo, memoria y representación. Adriana Cavarero y Judith Butler en diálogo (Barcelona: Icaria Editorial, 2014), 48.

3 Ibidem.

${ }^{4}$ David Harvey, Breve historia del Neoliberalismo (Madrid: Akal, 2007), 6.

${ }^{5}$ Roberto Bolaño, La literatura nazi en América (Barcelona: Anagrama, 2010), 55.
} 
a su pasado europeo, con el fin de cuidar la pureza racial, lo que les brinda mayores posibilidades de sobrevivir exentos de agresiones. En oposición complementaria a ese planteamiento de Salvático, la comunidad nativa de la antigua geografía prehispánica se haya en una condición de vulnerabilidad intencionada. Además, Salvático idea "el recorte de los derechos de los ciudadanos de origen judío", ${ }^{6}$ lo que significa mantenerlos también en una condición de vulnerabilidad exacerbada, pero con una justificación diferente a la que rige la de los nativos. Incluso, para atender el caso de la pureza racial se sugiere "la emigración masiva procedente de los países escandinavos para aclarar progresivamente la epidermis nacional oscurecida después de años de promiscuidad hispano-indígena". 7 Las propuestas presentadas en la obra de Salvático permiten comprender algunas vejaciones que se llevaron a cabo durante la dictadura, particularmente, con los poetas Cherniakovski y Martín García.

En las obras mencionadas de Bolaño se observa que la vulnerabilidad aparece como característica particular de personajes que cumplen con un patrón básico: son jóvenes, son poetas y, políticamente, tienen una postura distinta a la ideología del régimen dictatorial. Butler explica que "la vulnerabilidad [también es] entendida como posibilidad de destrucción por parte de los otros", 8 y es en este sentido que aparecen señalados personajes como las poetas y hermanas María y Magdalena Venegas, su tía, la empleada doméstica que las asistía en la casa de campo de Nacimiento, el poeta judío Juan Cherniakovski y el poeta Martín García, en el último capítulo de La literatura nazi.

En Estrella distante se refiere la desaparición forzada de casi toda una generación y se citan nombres específicos de escritoras de poesía que asistían al taller de Juan Stein como las hermanas Venegas, Patricia Méndez y Carmen Villagrán. Mientras que en Nocturno de Chile se narra con matices de leyenda urbana la intervención a una corporeidad anónima. Además de que la posibilidad es entendida como sinónimo de poder dañar al otro, “existen quienes creen que pueden decidir qué personas pueden habitar la Tierra". ${ }^{9}$ Por tanto, encuentro en estos relatos dos componentes principales que hacen posible que esos personajes sean asumidos como vidas no vivibles y ambos

\footnotetext{
${ }^{6}$ Ibidem.

${ }^{7}$ Ibidem.

${ }^{8}$ Butler, "Vida precaria", 73.

${ }^{9}$ Ibidem.
} 
responden a los planteamientos de Butler en cuanto a que hay sujetos que deciden quiénes deben morir y a la inducción de la vulnerabilidad entendida como la posibilidad de dañar intencionalmente a otros.

No se puede evitar mencionar que en los tres relatos el poder del sistema de la dictadura del General Augusto Pinochet toma vida en los personajes Ramírez Hoffman, Carlos Wieder y Jimmy Thompson, respectivamente. Hoffman, Wieder y Thompson representan la instauración de las políticas neoliberales y la limpieza ideológica comunista encarnada por Salvador Allende. La incidencia de estos personajes en la vida pública para disciplinar a la comunidad se da en el contexto del golpe de Estado en Chile el 11 de septiembre de 1973. David Harvey y Naomi Klein coinciden en que dicha espacialidad y temporalidad fue el escenario donde se implementó “el primer experimento de formación de un Estado neoliberal". ${ }^{10}$

Esta visión me apoya para respaldar que las corporeidades vulnerables y susceptibles son aquellas que impiden la perpetuación de un sistema, en este caso el neoliberal, que se despliega en las páginas de las referidas novelas de Bolaño. Según Harvey "el golpe contra el gobierno democráticamente elegido de Salvador Allende fue promovido por las élites económicas domésticas que se sentían amenazadas por el rumbo hacia el socialismo de su presidente. Contaron con el respaldo de compañías estadounidenses, de la CIA, y del secretario de Estado estadounidense Henry Kissinger". ${ }^{11}$ El enfrentamiento político al gobierno de Salvador Allende había estado latente desde que ejercía el poder y estaba integrado, principalmente, por las élites financieras que pertenecían a "el club de los lunes", asesorados por los "Chicago Boys". Al comienzo del periodo de polarización ideológica mundial, conocido como la Guerra Fría, el gobierno de Estados Unidos invirtió en la formación económica neoliberal de los "Chicago Boys", quienes mantuvieron una relación con el famoso club de los empresarios. ${ }^{12}$ Afirma Harvey que "Pinochet puso a estos economistas en el gobierno donde su primer trabajo fue negociar los créditos con el Fondo Monetario Internacional. El fruto de su trabajo junto al FMI fue la reestructuración de la economía en sintonía con

\footnotetext{
${ }^{10}$ Harvey, Breve historia del neoliberalismo, 20.

${ }^{11}$ Ibidem.

${ }^{12}$ Ibid., 14
} 
sus teorías". ${ }^{13}$ La consecuencia de ellos sería la liberación de "las restricciones reglamentarias"14 que afectarían directamente el mercado de trabajo, un ámbito que el comunismo defendía como portavoz del proletariado. En este contexto, en las novelas se puede comprender que la dictadura de Pinochet estaba alineada con los principios políticos de Estados Unidos y, por tanto, el enemigo era el comunismo que había que aniquilar.

\section{Arte fotográfico o el castigo ejemplar a las mujeres disidentes}

La decisión de la existencia o la anulación de la vida están relacionadas con las prácticas corporales políticas. Por tanto, es destacable que la subjetividad mantiene una relación intrínseca con el cuerpo que, siguiendo a Adriana Fuentes, es "parte del proceso de la subjetividad"15 y que, simultáneamente, "nos brinda ser visibles ante otros para desplazarnos y tener características que conforman la individualidad y al mismo tiempo saberse integrante de seres vivos pensantes y socializados". ${ }^{16}$ Las hermanas Venegas asistían al taller de poesía de Cherniakovski, espacio en donde es captable la constitución de su subjetivación mediante la lírica. En ese taller, las Venegas conocieron a Ramírez Hoffman, quien aparece ahí como aprendiz, “entonces se hacía llamar Emilio Stevens y escribía poemas que Cherniakovski no desaprobaba aunque las estrellas del taller eran las gemelas María y Magdalena Venegas". ${ }^{17}$ Implícitamente, en el relato se revela que la participación de Hoffman en el taller tenía como finalidad el espionaje para detectar a los disidentes del régimen dictatorial. Hoffman estaba ahí para sabotear la dignidad de esas vidas, entendiéndolo como que "los cuerpos se congregan precisamente para demostrar que son cuerpos, y para que quede políticamente claro lo que significa persistir como cuerpo en este mundo, qué requerimientos deben ser cumplidos para que los cuerpos sobrevivan, y

\footnotetext{
${ }^{13}$ Ibidem.

${ }^{14}$ Ibidem.

15 Adriana Fuentes, "El cotidiano periplo entre ingesta y corporeidad. Implicaciones de una salud normalizada”, en Mauricio List Reyes y Fabián Giménez Gatto (coords.), Tratado breve de concupiscencias y prodigios (Puebla: Benemérita Universidad Autónoma de Puebla, 2017), 190.

${ }^{16}$ Ibidem.

${ }^{17}$ Bolaño, La literatura nazi, 189.
} 
qué condiciones hacen que una vida corporal, la única que tenemos, sea finalmente digna de vivir". ${ }^{18}$ Llama la atención que tanto en La literatura nazi, como en Estrella distante, los narradores hagan una focalización especial en la relación de interdependencia entre Hoffman/Wieder, las hermanas Venegas/Garmendia, Patricia Méndez, Carmen Villagrán y otras mujeres anónimas. Esta distinción me posiciona en una lectura interpretativa de los crímenes hacia estos personajes como un feminicidio, puesto que a todas ellas las aborda intimando en una relación de amistad, con sesgo de coqueteo y en ambos relatos son exhibidas en una exposición fotográfica que es referida como el nuevo arte. ${ }^{19}$ A diferencia de Nocturno de Chile, en donde se alude a las desapariciones forzadas como un acto de detención y reclutamiento en los cuárteles militares o laboratorios clandestinos en donde serían torturados. Sin embargo, todos los crímenes apuntan hacia un fin último, desaparecer toda célula posible de comunismo.

Una de las reflexiones de Adriana Fuentes que me interesa destacar es la que menciona que "el sujeto [...] al estar atravesado por categorías como el género, la sexualidad y la edad, se le han atribuido aseveraciones que se asemejan al ámbito de lo preexistente e incambiable". ${ }^{20}$ Con las mujeres, Emilio Stevens planeaba un cortejo, "pololeaba [...] con María Venegas", 21 aunque en el relato también se puntualiza que "en realidad salía a menudo con las dos hermanas, iban al cine, a conciertos, al teatro, a conferencias [...] a veces iban en el coche de las Venegas, un Volkswagen escarabajo blanco, a la playa a contemplar los atardeceres del Pacífico, fumaban yerba juntos". ${ }^{22}$ En el caso del personaje de Carmen, cuando su madre le pregunta, aquella última tarde en que vio a su hija, quién era el amigo con quien tendría la cita, ésta le respondió "desde la puerta [...] que un poeta". ${ }^{23}$ La escritura de Bolaño demuestra una gran astucia para hablar de los feminicidios, puesto que no se enfoca en describirlos con exactitud. En cuanto a la fase del cortejo, los narradores de ambos relatos se extienden en el desarrollo de la relación con las hermanas Venegas/Garmendia.

\footnotetext{
${ }^{18}$ Judith Butler, "Vulnerabilidad corporal, coalición y política de la calle". Nómadas (Col), núm. 46 (abril, 2017): 16.

${ }^{19}$ Roberto Bolaño, Estrella distante (Barcelona: Anagrama, 2010), 200.

${ }^{20}$ Fuentes, "El cotidiano periplo", 191.

${ }^{21}$ Bolaño, La literatura nazi, 189.

${ }^{22}$ Ibidem.

${ }^{23}$ Bolaño, Estrella distante, 49.
} 
[T]ocan a la puerta y allí está Emilio Stevens y las Venegas se alegran de verlo, lo acosan a preguntas, lo invitan a cenar y después le dicen que puede quedarse a dormir y durante la sobremesa probablemente leen poemas, Stevens no, él no quiere leer nada, dice que está preparando algo nuevo, se sonríe, adopta una actitud misteriosa, o tal vez ni siquiera se sonríe, dice secamente que no y las Venegas asienten. ${ }^{24}$

La descripción de la relación entre el poeta espía y la poeta Carmen se reduce a una cita en el cine con un poeta, mientras que del galanteo con Patricia no se menciona nada. No obstante, escenas más adelante, en las escrituras en los cielos en las que "Ramírez Hoffman estaba nombrando, conjurando, a mujeres muertas", 25 aparece el nombre de Patricia, entre otros. Por los indicios del texto, se puede aseverar que Stevens/Ruiz-Tagle "era guapo, era inteligente, era sensible", ${ }^{26}$ consecuentemente usa estas cualidades para atraer a sus víctimas y proporcionarles un castigo ejemplar.

Sostengo que la premisa principal por la que tales personajes son asumidas como vidas no vivibles es el ejercicio de su disidencia política. Bolaño juega con dos miradas, con la que comúnmente visibiliza la precariedad y con la que quiere demostrar a sus lectores que son sujetos que importan. En el relato hay varios intersticios que dejan ver que la condición económica es un factor sustancial para que desde la perspectiva sistémica hegemónica sean o no vidas lloradas. Tanto en La literatura nazi como en Estrella distante, entre los personajes de las mujeres, los más explicados son los de las hermanas Venegas/Garmendia, como si el narrador tuviera mayor interés en recordarlas a ellas. Cuando sucedió el golpe de Estado, “se encerraron en su casa, una de las más grandes del pueblo [...] en una casa de madera de dos pisos que había pertenecido a la familia del padre, con más de siete habitaciones y un piano". ${ }^{27}$ Las características de la casa sugieren confort, riqueza material, ciertos lujos herencia de sus padres, fortuna que respaldaba la solvencia económica de las hijas. La descripción que hace el narrador refiere a una condición acaudalada, por lo que se descarta que el móvil de su precarización sea su condición económica. Sin embargo, el narrador también visibiliza

\footnotetext{
${ }^{24}$ Bolaño, La literatura nazi, 191.

25 Ibid., 195.

${ }^{26}$ Ibid., 189-190.

${ }^{27}$ Ibid., 190.
} 
otros aspectos que configuran la subjetividad de estas corporeidades, como su valentía: "las Venegas no eran lo que se dice unas muchachas cobardes, todo lo contrario". ${ }^{28}$ Derivo que el dominio de las Venegas, simbolizado en el escenario de la casa, es reivindicado haciendo referencia a su valentía y al cuidado "de la tía que las guardaba de todo mal". ${ }^{29}$ Sin embargo, los elementos formales como escenario y personajes que configuran cierto poderío son degradados por el poder de Ramírez Hoffman. Los personajes de las hermanas contrastan con el de Edelmira Thompson de Mendiluce, quien en "sus primeros poemas, como es lógico suponer, habla [...] de sentimientos filiales, pensamientos religiosos y jardines. Quien también coqueteó con la idea de hacerse monja". ${ }^{30}$ Los personajes de las hermanas Venegas y su tía no están configurados por características socialmente regladas para las mujeres. Tanto la tía, como las Venegas/Garmendia no tenían una relación romántica exclusiva. Dentro de sus prácticas corporales están las citas con sus amigos, divertirse, ir al cine, así es como Ramírez Hoffman se aproxima a ellas, y ellas salen con él, lo reciben en su casa de campo, lo invitan a que pase ahí la noche. La condición socioeconómica de estos personajes no es un impedimento para los objetivos de Hoffman. Aisladas en la casa de campo, experimentan la desprotección que evidencia su vulnerabilidad y, debido de su participación en el taller de poesía de Cherniakovski, son secuestradas por el joven poeta y espía de la dictadura.

El narrador de Estrella distante refiere el testimonio del personaje de Bibiano O’Ryan para señalar que durante la dictadura "habían desaparecido casi todos nuestros amigos", ${ }^{31}$ incluyendo a las mujeres. "Todas las poetisas están muertas, dijo. Ésa es la verdad". ${ }^{32}$ Entre ellas, Patricia Méndez y Carmen Villagrán, ambas poetas asistentes al taller de Juan Stein. "La poeta Carmen Villagrán [...] desapareció en los primeros días de diciembre" 33 y Patricia Méndez "de diecisiete años, perteneciente a un taller de literatura gestionado por las Juventudes Comunistas [desapareció] por las mismas fechas que Carmen

\footnotetext{
${ }^{28}$ Ibidem.

${ }^{29}$ Ibidem.

${ }^{30}$ Ibid., 13.

${ }^{31}$ Bolaño, Estrella distante, 47.

32 Ibid., 49.

${ }^{33}$ Ibidem.
} 
Villagrán". ${ }^{34}$ Las Garmendia, Carmen, Patricia asistían al taller y escribían poesía, práctica que las visibiliza vulnerables por estar vinculada al desempeño de género discordante de la heteronormatividad y a su simpatía con el comunismo. Desprendo de ello que la elección de Wieder está guiada por cómo ellas se subjetivan así mismas.

Sin embargo, en el relato se da cuenta de que una vez sustraídas de sus domicilios o secuestradas, la posibilidad de que estos personajes sean llorados depende de su condición económica. Veamos cómo los rasgos que aluden a la manera en que ellas se subjetivan, marcan la pauta y complementan la interpretación sobre su poder adquisitivo. "La diferencia entre ambas era notable, Carmen leía a Michel Leiris en francés y pertenecía a una familia de clase media; Patricia Méndez, además de ser más joven, era una devota de Pablo Neruda y su origen era proletario". 35

En el caso de Carmen, la adquisición de la lengua del conocimiento puede estar asociada a la solvencia económica de la clase media aburguesada o al ser autodidacta. Poniendo atención en la cita, el personaje de Patricia no es caracterizado por el conocimiento de otro idioma, empero se refiere el origen obrero de su familia. Con estas reivindicaciones a la cita, quiero hacer notar que hay una perspectiva del narrador que las dibuja por el contexto económico en que ellas conforman su subjetividad.

En ese sentido, infiero que Bolaño considera inserta en su narrativa la visión neoliberalista como una manera de desentrañar su complejidad y comprender que, en comparación a Patricia, sea notorio que la existencia de Carmen es llorada por sus familiares. Ello demuestra que la situación financiera es fundamental para la percepción que se tiene del duelo y la vulnerabilidad. En el relato se revela que Carmen es buscada por sus padres y por la comunidad religiosa a la que pertenece su familia. Sus redes de apoyo son válidas por el poder simbólico que representan. Por tanto, su búsqueda es un signo visible de que su muerte importa por haber asistido a la universidad, por pertenecer a una iglesia o por ser reconocida en una clase media aburguesada.

Entretanto, Patricia "no estudiaba en la universidad, como Carmen, aunque aspiraba algún día a estudiar pedagogía; trabajaba [...] en una tienda de electrodomésticos", ${ }^{36}$

\footnotetext{
${ }^{34}$ Ibidem.

${ }^{35}$ Ibidem.

${ }^{36}$ Ibidem.
} 
razones por las que en el relato no se manifiesta el valor que su muerte pudo haber recibido. Excepto la visibilización que el personaje de Bibiano O’Ryan hace al contar que visitó a su madre y "pudo leer en un viejo cuaderno de caligrafía algunos poemas de Patricia", 37 a los que calificó como una mezcla mala entre Incitación al nixonicidio y los Veinte poemas de amor, de Pablo Neruda.

Palabras como "frescura, asombro, ganas de vivir" 38 son las que dibujan con un poco de mayor nitidez la subjetivación por la que atravesaba el personaje de Patricia desde la mirada de Bibiano O’Ryan. Éste, a modo de duelo, escribe en la carta que le envió al narrador del relato "no se mata a nadie por escribir mal, menos si aún no ha cumplido los veinte años". ${ }^{39}$ Referir que en sus escritos se hallaba frescura, asombro o ganas de vivir es hacerla notar como una corporeidad que sí importa porque la subjetivación mediante la poesía reproducía una alternativa a las prácticas corporales hegemónicas. Entre ambos personajes se presentan discrepancias en relación a su situación económica. No obstante, una similitud es que ambas eran participes del taller de Juan Stein.

En ese sentido, su vulnerabilidad es señalada por una cuestión de género, por su condición económica y por su postura política. El análisis de los atributos y circunstancias de esos dos personajes ya mencionados da cuenta de la fusión de sus condiciones que recaen en la acepción sobre cómo deben ser tratadas sus corporeidades. Sin embargo, en ambos casos, como en el de las hermanas Venegas/Garmendia y de los poetas que se mencionan más adelante. No obstante, se puede entrever que son personajes que están constituyendo su subjetividad de una manera consciente, fuerte, pues se saben vulnerables y lo expresan mediante los poemas, al mismo tiempo, la poesía los acompaña en su encuentro y visión de la realidad. No obstante, pese a que las normas y la violencia dirigida hacia ellos son históricas, exploran otras prácticas corporales, como conocer otras lenguas para interpretar y leer a otros poetas o asistir a un taller de poesía dirigido por un comunista, así como practicar la descripción de sí mismos, reescribirse y reinventarse a través de la lírica.

La exposición fotográfica organizada por Hoffman/Wieder es la presentación explícita de la vulnerabilidad de las mujeres desaparecidas, principalmente. Si bien los

\footnotetext{
${ }^{37}$ Ibid., 42.

${ }^{38}$ Ibid., 42-43.

${ }^{39}$ Ibid., 43.
} 
testimonios citados por el narrador refieren la presencia de corporeidades de hombres, los cuerpos que protagonizan las fotos corresponden a mujeres. "Según Muñoz Cano, en algunas de las fotos reconoció a las hermanas Garmendia y a otros desaparecidos. La mayoría eran mujeres. El escenario de las fotos casi no variaba de una a otra por lo que deduce es el mismo lugar". ${ }^{40}$ La violencia cometida contra estos personajes tuvo dos fines. El fin último era la aniquilación de las ideas y prácticas de sesgo comunista. Sin embargo, también tuvo el propósito de exponer sus cuerpos torturados, destazados y destruidos, en algunos casos vivos, ${ }^{41}$ enmarcados como arte. La elección de las víctimas de Wieder estuvo pautada por un marco normativo de la dictadura que justifica la supresión de la existencia de los disidentes políticos. Bolaño evidencia la importancia que tenía para el régimen encarnado en Wieder - difundir el miedo con fotografías en las que se podía observar, seguramente, la zozobra de las víctimas. La advertencia clara y frontal estaba dirigida a los simpatizantes de la dictadura y seguidores de Wieder que esa noche se encontraban a la expectativa del nuevo arte. Para Wieder, el fotógrafo, retratar estas corporeidades pudo significar éxtasis y gratificación por el castigo que les estaba infligiendo a esas mujeres que físicamente eran las idóneas para la heteronormatividad. Referir que la similitud de estas mujeres a los maniquíes conduce a la interpretación de que Wieder seleccionaba a sus víctimas acorde a un estereotipo de belleza canónico afín al europeo. Así como en el relato se citan nombres de personajes mujeres, otras son enunciadas anónimas. Por tanto, asumo que describir algunos rasgos de su subjetivación, haciendo notar sus nombres, es sinónimo de que quienes no son nombradas son vidas menos merecedoras de duelo para Bolaño, en comparación a aquellas que reconoce su identidad.

Hasta aquí se ha mostrado que la narrativa de Bolaño presenta una dinámica de interdependencia que, en términos de Butler, "nos constituye no sólo como seres pensantes, sino de hecho, como seres sociales y corporales, vulnerables y apasionados". ${ }^{42}$ Sin embargo, en las novelas se lee un modelo de interdependencia en el que se cruzan la poesía, el arte, la sensibilidad, la alternancia, el castigo severo, la violencia, la exhibición, el miedo y la disciplina. Asimismo, existe un pensamiento que niega la vulnerabilidad como una

\footnotetext{
${ }^{40}$ Ibid., 97.

${ }^{41}$ Bolaño, Estrella distante, 97.

42 Judith Butler, Vida precaria. El poder del duelo y la violencia (Buenos Aires: Editorial Paidós, 2004$) 74$.
} 
característica inherente al ser humano y la afirma "como posibilidad de destrucción". ${ }^{43}$ Con ello, podría afirmarse que Carlos Wieder actúa con la certeza de que esos cuerpos no son protegidos por el Estado, ya sea por disidencia política, por su práctica escritural de poesía o por una cuestión de género que se manifiesta en su exposición fotográfica. Sin embargo, más allá de tales aspectos, la exposición fotográfica es la lección para los espectadores sobre lo que puede suceder a los discrepantes de la dictadura.

La interdependencia no sólo se despliega con las corporeidades de pensamiento discordante, sino que también se desdobla un vínculo mezquino con quienes integran las instituciones policiacas o militares. La exposición fotográfica es irrumpida por personal de inteligencia para suspender la exhibición: "cuando aún faltaba bastante para que amaneciera, aparecieron tres militares y un civil que se identificaron como personal de Inteligencia" ${ }^{44}$ En otras palabras, lo que al régimen dictatorial le motiva a evitar que se continúe con la exposición es la visibilidad del crimen, más no el crimen en sí. Los expectantes creyeron que la visita del Servicio de Inteligencia tenía intenciones de detener a Wieder. Sin embargo, no fue así. En palabras del narrador, los visitantes a la exposición terminaron por considerar que los militares estaban "entregados en cuerpo y alma a su trabajo" y que habían llegado a "horas intempestivas a hacer limpieza" ${ }^{45}$ La novela no explica por qué los asistentes a la exposición creían que el Servicio de Inteligencia detendría a Wieder, sin embargo, se puede leer entre líneas la percepción represora que tenían de las instituciones. Tanto los espectadores, como los militares y espías recibían también la lección transmitida mediante el arte: las mujeres discordantes de la heteronormativdad y disidentes políticas recibirían un castigo severo y serían exhibidas porque las prácticas de Wieder están respaldadas por una ideología y un Estado que justifica y legitima la violencia a corporeidades sistemáticamente señaladas vulnerables.

Por ello sustento que los feminicidios son resultado de la violencia de Estado, encarnado en un Hoffman/Wieder fascinado "como pocos en su lucha contra el comunismo". ${ }^{46}$ Sus compañeros militares y aliados para el propósito de reprimir cualquier brote de insurrección ideológica dicen que "Ramírez Hoffman tenía toda la razón del

\footnotetext{
${ }^{43}$ Ibid., 73.

${ }^{44}$ Bolaño, La literatura nazi, 100.

${ }^{45}$ Ibidem.

${ }^{46}$ Bolaño, Estrella distante, 205.
} 
mundo cuando decía que no había que dejar vivo a ningún prisionero a quien previamente se hubiera torturado". ${ }^{47}$ En tal contexto, quizás no se pueda asegurar que existe una desprotección del Estado, sino que es el mismo Estado, encabezado por la dictadura, el que ordena la violencia sistemática con fines políticos. En el particular caso de Ramírez Hoffman/Wieder la exposición fotográfica la realiza a título personal, sin embargo, fue posible a consecuencia de las circunstancias represoras de la dictadura militar.

\section{La justificación étnica y nativa de la violencia}

En La literatura nazi en América la violencia de Estado también es representada mediante la desaparición forzada de hombres como un suceso normal, ya que "por aquellos días desaparece mucha gente, desaparece Juan Cherniakovski, el poeta judío del sur". ${ }^{48}$ El pensamiento de Hanna Arendt arroja luz para comprender que las desapariciones son parte de la noción de "la violencia administrada en beneficio del poder (y no de la ley)", 49 lo cual "se convierte en un principio destructivo que no se detendrá hasta que no quede nada que violar". ${ }^{50}$ Esto coincide con el punto de vista de David Harvey, quien afirma que la implementación de nuevas políticas económicas de la escuela neoliberal trajo consigo la represión "de manera violenta todos los movimientos sociales y las organizaciones políticas de izquierda y desmanteló todas las formas de organización popular (como los centros de salud comunitarios de los barrios pobres) que existían en el país".51

Ex agentes de la Dirección de Inteligencia Nacional han hecho declaraciones recientemente, una de ellas es la de Jorgelino Vergara, quien afirmó que el cuartel Simón Bolívar fue "el reducto más secreto que alguna vez tuvo" 52 la DINA, en el cual eran torturados y asesinados "a quienes la dictadura consideraba sus enemigos, utilizando los métodos más violentos y crueles que alguien se pudiera imaginar". ${ }^{53}$ Esto confirma que

\footnotetext{
${ }^{47}$ Bolaño, La literatura nazi, 204.

${ }^{48}$ Ibid., 191.

${ }^{49}$ Hanna Arendt, Los orígenes del totalitarismo (Madrid: Santillana, 1998), 127.

${ }^{50}$ Ibidem

${ }^{51}$ Harvey, Breve historia, 20.

${ }^{52}$ Carlos Basso, Chile top secret (México: Aguilar, 2017), 12.

${ }^{53}$ Ibidem.
} 
existe una mirada generalizada sobre el cuerpo que Bolaño plantea en sus novelas: las corporeidades de quienes no comparten los ideales neoliberales deben ser torturados. Simultáneamente, esta práctica reiterativa conduce a la normalización de la vulnerabilidad intencionada. La desaparición del poeta y tallerista Juan Cherniakovski se asume como un hecho normalizado dado su contexto. En el libro se refiere explícitamente que "todo el mundo piensa es normal que el cabrón rojo desaparezca". 54 La palabra "rojo" puede explicar que el hecho se comprenda como algo normal. El principal y abarcador color de la bandera comunista es rojo y la supresión de estas corporeidades se concibe como un suceso lógico por no ser un afiliado al régimen, mecanismo entre el Estado y la sociedad desplegados en La literatura nazi en América, Estrella distante y Nocturno de Chile. Sin embargo, las desapariciones de personajes como Cherniakovski o Martín García están enmarcadas por una justificación étnica o de pigmentación de la piel.

Martín García “tenía su taller de poesía en la Facultad de Medicina, amigo y rival de Cherniakovski". ${ }^{55}$ En comparación a la de Cherniakvoski la desaparición de García resultó más que normal, indiferente: "nadie lo echó en falta", 56 no obstante la indiferencia: "a muchos les hubiera gustado su muerte". ${ }^{57}$ En otras palabras, el texto refleja muy bien que a esas afirmaciones les subyace cierto placer ante el asesinato de corporeidades como de Martín García excluido por marcas como su procedencia nativa y la pigmentación de su piel. Esto tiene resonancia en el planteamiento de Butler quien asume que "la frialdad con pretensiones de superioridad no sólo es necesaria para matar, sino también para contemplar la destrucción de la vida con satisfacción moral, incluso con un sentimiento de triunfo moral", 58 Por tanto, la moral del Estado dictatorial también se sostiene en la normalización de ciertos crímenes diferenciados por características de predominancia étnicas pues Cherniakovski era "alto y rubio" ${ }^{59}$ y Martín García "bajito y moreno". ${ }^{60}$ Es interesante que Bolaño muestre cómo estas características pesaban para la sociedad chilena de esa época al repensar “¿cómo era posible que ese indio pequeñajo y feo tradujera y se carteara con Alain

\footnotetext{
${ }^{54}$ Bolaño, Estrella distante, 191.

${ }^{55}$ Ibid., 195.

${ }^{56}$ Ibidem.

${ }^{57}$ Ibidem.

${ }^{58}$ Butler, Vida precaria, 34.

${ }^{59}$ Bolaño, Estrella distante, 195.

${ }^{60}$ Ibidem.
} 
Jouffroy, Denis Roche, Marcelin Pleynet?”. ${ }^{61}$ Poetas “que en Chile nadie salvo él conocía. Y eso le daba mucha rabia a mucha gente". ${ }^{62}$ Esto abre otra discusión sobre el tema de la raza y la etnicidad. Verena Stolcke apunta a que la raza o las características étnicas son "una construcción simbólica que se utiliza en ciertas circunstancias sociopolíticas como criterio de definición y delimitación de grupos humanos". 63

En ese sentido, el texto revela la persistencia de un saber que relaciona la inteligencia con las marcas corporales europeas, principalmente con las definidas por el nazismo. Por tanto, la vulnerabilidad intencionada no sólo es explícita con las desapariciones forzadas sino que justificada para normativizar el crimen, puesto que la cita “nadie lo echó en falta” subraya que la muerte del poeta Martín García no es merecedora de duelo. La alegría por su muerte se basa en sus marcas corporales, en la configuración de su subjetividad caracterizada por el dominio de la poesía en la lengua francesa y por su disidencia política.

Dicho de otro modo, en esta investigación se distinguen diversas posiciones sociales precarias regidas por signos corpóreos. A partir de los personajes de Bolaño se observa que poseer un color de piel con pigmentación clara, predominantemente es indicio de ascendencia europea y conlleva la tendencia de una posición económica privilegiada. Sin embargo, la procedencia de los judíos se remonta al medio oriente, por tanto, se reivindica su exclusión del modelo deseado por los nazis que, a su vez, inspira a varios escritores de América y, consecuentemente, la normalización de las desapariciones de sujetos con estas características corpóreas. Personajes que presentan una pigmentación con tendencia a los tonos oscuros o una estatura menuda, sus vidas obtienen la indiferencia, incluso, la deseabilidad de su muerte, puesto que tales rasgos son indicio de su etnicidad prehispánica configurada como indeseable desde el estereotipo disímil europeo. Este último se sustenta en un saber histórico ${ }^{64}$ que ha infundido que estas generalizaciones de lo blanco, lo claro y lo occidental pertenecen a un grupo social prestigioso que sí merece vivir.

\footnotetext{
${ }^{61}$ Ibidem.

${ }^{62}$ Ibidem.

${ }^{63}$ Verena Stolcke, “¿Es el sexo para el género lo que la raza para la etnicidad... y la naturaleza para la sociedad?", Política y Cultura, núm. 14 (2000), 41.

64 Elsa Muñiz, "Pensar el cuerpo de las mujeres: cuerpo, belleza y feminidad. Una necesaria mirada feminista”. Revista Sociedade e Estado, 29, núm. 2. (mayo-agosto 2014): 416.
} 
La exposición de las vidas torturadas y desaparecidas en Nocturno de Chile aparece asociada a la desavenencia política. A diferencia de las novelas La literatura nazi o Estrella distante, en Nocturno de Chile la descripción es generalizada, puesto que no se presenta explícitamente que los rasgos como el género o marcas corpóreas sean determinantes en su desaparición forzada. En esta novela sólo se muestra la vulnerabilidad exacerbada de la que fueron víctimas algunas corporeidades en el periodo de la represión política llevado a cabo por los integrantes de la Dirección de Inteligencia Nacional fundada por la dictadura militar. Aunado a la circunstancia de las víctimas, la novela "está atravesada por la complicidad de literatos e intelectuales", ${ }^{65}$ cruces con los que Bolaño da cuenta de los personajes que sí importan.

La violación de derechos sucede en consecuencia a eliminar fuerzas que se opusieran al interés primordial de poner en funcionamiento políticas económicas neoliberales en un periodo en el que el comunismo era una práctica política viable que la Revolución cubana había hecho posible. David Harvey propone que "los fundadores del pensamiento neoliberal tomaron el ideal político de la dignidad y de la libertad individual como pilar fundamental, que consideraron 'los valores centrales de la civilización", 66 valores que "se veían amenazados no sólo por el fascismo, las dictaduras y el comunismo, sino por todas las formas de intervención estatal que sustituían con valoraciones colectivas de libertad de elección de los individuos". ${ }^{67}$ Esto conlleva a vislumbrar que en la novela de Bolaño se plantea la alianza entre el sistema dictatorial y el neoliberal en función de los intereses de Estados Unidos de acabar con el comunismo y de implementar la privatización como estrategia económica. En consecuencia, los personajes visibilizados por su vulnerabilidad serán objeto de tortura y desaparición en tanto se encuentren involucrados en prácticas corporales opuestas a las esperadas por el nuevo régimen.

Más allá de los límites de la ficción, diversas fuentes han develado que la escritora Mariana Callejas y su esposo Michael Townly eran agentes de la Dirección de Inteligencia Nacional y en su casa en el barrio Lo Curro, en Santiago de Chile, tenían un laboratorio

\footnotetext{
${ }^{65}$ Roberto González, "Nocturno de Chile y el canon”, Acta Literaria, núm. 41 (II Sem., 2010): 120.

${ }^{66}$ Harvey, Breve historia, 11.

${ }^{67}$ Ibidem.
} 
clandestino que operaba simultáneamente a las "concurridas tertulias literarias" 68 y "asados dominicales [...] en los que participaban los más violentos oficiales de la Dina", 69 responsables de las operaciones para la detección, tortura y desaparición de los señalados comunistas. En Nocturno de Chile, Mariana Callejas es ficcionalizada en el personaje de María Canales. Entre las diversas escenas en que aparece dicho personaje citado indirectamente, se encuentra el famoso episodio en el que durante una tertulia literaria uno de los invitados se pierde dentro de la casa en su intento de ir al sanitario y abrir una puerta en la que, siguiendo a Bolaño encuentra "una especie de cama metálica. Encendió la luz. Sobre el catre había un hombre desnudo, atado a las muñecas y de los tobillos. Parecía dormido, pero esta observación es difícil de verificar, pues una venda le cubría los ojos". ${ }^{70}$ Sin embargo, el castigo, su exacerbada vulnerabilidad expuesta inicia desde que estos sujetos son visibilizados por su disidencia política y tiene continuidad en su detención y se hace explícita en la novela de Bolaño a partir de un testimonio oral transmitido por generaciones. En el testimonio observo lo que Butler explica respecto a la vulnerabilidad inducida como carencia de control ante las agresiones de otros, puesto que se referencia una corporeidad descrita por "sus heridas, sus supuraciones [...] las partes maltratadas de su anatomía, las partes hinchadas, como si tuviera más de un hueso roto". ${ }^{71}$ Suplicio inducido por disposición de Jimmy Thompson, personaje que ficcionaliza a Michael Lowry.

La astucia de Bolaño para nombrar lo que sí importa se centra en descripciones breves sobre lo que aquí se entiende por vulnerabilidad intencionada. De esta manera, la escritura de Bolaño recurre a la configuración de personajes anónimos que simbolizan al grupo de víctimas de la guerra sucia acaecida en Chile en esta época. Esta breve escena en la que sólo se aprecia a un sujeto con determinantes signos de martirio refiere parcialmente al proceso al que fueron sometidos los hombres, una punición distinta a la de las mujeres. Otro aspecto importante a destacar de esta escena, son las distorsiones del narrador y su guiño a la fragilidad de la memoria histórica. Por un lado, se dice que quien "se había perdido era un autor de teatro o tal vez un actor", 72 y, por el otro, que "fue un teórico de la

\footnotetext{
${ }^{68}$ Basso, Chile top, 15.

${ }^{69}$ Ibidem.

${ }^{70}$ Bolaño, Nocturno de Chile, 139.

${ }^{71}$ Ibid., 140.

${ }^{72}$ Ibid., 139.
} 
escena de vanguardia el que se perdió por los corredores burlones de la casa en los confines de Santiago". ${ }^{73}$ Además de que Bolaño plantea los deslices de la remembranza, se podría estar bosquejando la complicidad de los artistas y escritores que asistían a las tertulias sobre lo que sucedía clandestinamente en la casa María Canales, puesto que era una historia que muchos sabían y divulgaban: "meses después, tal vez años después, otro habitual de las veladas me contó la misma historia. Y luego otro y luego otro y otro más". ${ }^{74}$ Independientemente de lo ambiguo que pueda ser, ambas interpretaciones son posibles en el universo narrativo de Bolaño. El sobrentendido de la multiplicidad de cómplices anónimos representados en el "otro y luego otro" simboliza también la complejidad del anonimato de todos los desaparecidos de aquel periodo histórico. Por muy breve que sea la narración de la escena, es un mérito de Bolaño revertir la visión normalizada de quienes por "equivocación" abrían la puerta del laboratorio, veían y la cerraban para volver a la reunión. Sin embargo, ese “otro, otro y otro" también nombra a los desaparecidos, a través de la voz de miedo o humor de los compinches de Canales y Thompson. El testimonio del actor de teatro sugiere que "el extraviado o la extraviada cerró la puerta, desaparecida instantáneamente la borrachera, y descorrió sigilosamente el camino andado". ${ }^{75}$ Hay un miedo implícito que se expresa con el desvanecimiento de la embriaguez al percatarse de quien se encontraba en la camilla de metal con marcas de violencia. También se traza la posibilidad de que el "teórico con un gran sentido del humor [...] al extraviarse no se arredró, pues a su sentido del humor añadía una curiosidad natural, y que al verse y saberse perdido en el sótano de María Canales no tuvo miedo, sino que más bien se despertó su espíritu fisgón, y que abrió puertas y que incluso se puso a silbar". ${ }^{76}$ La polifonía como estilo particular de Bolaño es una estrategia narrativa para inducir al lector en una reflexión sobre la complejidad de los sujetos y para desnormalizar las vejaciones a las que fueron sometidos todos aquellos simpatizantes del comunismo que asistían a los talleres de poesía, personajes que importan a Bolaño y que leían a poetas en otros idiomas, artistas plásticos, escritores de su propia obra poética no publicada que representaron una alternativa de configuración de la subjetividad a las heteronormativas de la dictadura.

\footnotetext{
${ }^{73}$ Ibid., 149.

${ }^{74}$ Ibid., 141.

${ }^{75}$ Ibid., 139.

${ }^{76}$ Ibid., 140.
} 


\section{Las corporeidades que importan a Roberto Bolaño}

A lo largo de este artículo de investigación, he mostrado que Bolaño asume al cuerpo desde una postura en la que aborda tanto la inevitable complicidad de quienes testimoniaron la tortura, como lo que significaba la poesía para los disidentes políticos que asistían al taller de Cherniakovski. Sin embargo, más allá de dar cuenta de la natural complejidad de todas las corporeidades, la escritura de Bolaño pone un énfasis sutil en los personajes que, desde la perspectiva neoliberal han pasado a la historia como un peligro para la sociedad. Por tanto, la obra de Bolaño pone de manifiesto que la práctica de la poesía ejercida por personajes como las hermanas Venegas, Patricia, Carmen, Martín García o Cherniakovski formaba parte de una subjetividad que se constituía alterna a las prácticas heteronormativas aprobadas por el naciente neoliberalismo de Chile en esa época. En otras palabras, Bolaño visibiliza a estos personajes reescribiéndolos como hacedores de caminos, conscientes de que la vulnerabilidad es una realidad inevitable. 


\section{Bibliografía}

Arendt, Hanna. Los orígenes del totalitarismo. Madrid: Santillana, 1998.

Bolaño, Roberto. Nocturno de Chile. Barcelona: Anagrama, 2009.

Bolaño, Roberto. La literatura nazi en América, Barcelona: Anagrama, 2010.

Bolaño, Roberto. Estrella distante. Barcelona: Anagrama, 2010.

Basso, Carlos. Chile top secret. México: Aguilar, 2017.

Butler, Judith. "Vida precaria, vulnerabilidad y ética de cohabitación". En Begonya Saez Tajafuerce (ed.), Cuerpo, memoria y representación. Adriana Cavarero y Judith Butler en diálogo. Barcelona: Icaria Editorial, 2014.

Butler, Judith. Vida precaria. El poder del duelo y la violencia Buenos Aires: Editorial Paidós, 2004.

Butler, Judith. "Vulnerabilidad corporal, coalición y política de la calle". Nómadas (Col), núm. 46 (abril, 2017): 13-30.

Fuentes, Adriana. "El cotidiano periplo entre ingesta y corporeidad. Implicaciones de una salud normalizada”. En Mauricio List Reyes y Fabián Giménez Gatto (coords.), Tratado breve de concupiscencias y prodigios. Puebla: Benemérita Universidad Autónoma de Puebla, 2017.

González Echevarría, Roberto. "Nocturno de Chile y el canon”. Acta Literaria, núm. 41 (II Sem., 2010): 117-128.

Harvey, David. Breve historia del Neoliberalismo. Madrid: Akal, 2007.

López, Ignacio. "Malestar en la literatura: escritura y barbarie en Estrella distante y Nocturno de Chile de Roberto Bolaño". Revista Chilena de Literatura, núm. 20 (2020): 199-215.

Muñiz, Elsa. "Pensar el cuerpo de las mujeres: cuerpo, belleza y feminidad. Una necesaria mirada feminista”. Revista Sociedade e Estado, 29, núm. 2 (mayo-agosto, 2014).

Stolcke, Verena. “¿Es el sexo para el género lo que la raza para la etnicidad... y la naturaleza para la sociedad?”. Política y Cultura, núm. 14 (2000): 25-60. 